\title{
SENDAI FRAMEWORK FOR MANAGING MIGRANT CRISIS - CASE OF SERBIA
}

\author{
Ivica Lj. Đorđević, PhD \\ Faculty of Security Studies, University of Belgrade, \\ E-mail: djivica@gmail.com \\ Zoran Keković, PhD \\ Faculty of Security Studies, University of Belgrade, \\ E-mail: zorankekovic@yahoo.com
}

\section{Abstract}

Sendai framework is an attempt by the international community to adequately respond, primarily to climate, and other challenges confronted by modern civilization. A multi-sector approach is in line with the complexity of the problems faced by people regardless of their status, national origin and government. The global system of prevention and disaster response this time is more likely to succeed because it provides a methodological framework by means of which should be evaluated the results and the execution of commitments. A more responsible attitude towards natural resources and the social environment contributes to a qualitative change in the life conditions of people in an area. Raising the efficiency of the institutional system and the preservation of natural resources affects the basic factors of the migratory movements of people.

The example of Serbia in many ways demonstrates that the international community has not had an adequate attitude towards the problems in the functioning of the system. Dissatisfaction in the wake of the democratic changes in 2000 many citizens of Serbia initiated to search for better living conditions. Departure of highly qualified workers and tycoonisation of economy led to a situation in which the Republic of Serbia is unable to solve its existing systemic problems on its own. According to the Sendai framework the international community should take certain steps to help countries like Serbia to reform the system and apply those standards that would contribute to solving internal problems. Raising the level of functionality of the system institutions, as well as the application of standards in terms of performance of the system institutions, as well as the application of standards in terms of performance of the obligations of large transnational economic systems in addition to contributions in relation to coping with disasters would also solve part of the problems underlying the migratory movements.

Key words: Sendai framework, disasters management, Migrations, Human security 


\section{Introduction}

The current migrant crisis has shown that the international community does not have adequate mechanisms aimed at responding to mass migrations. Bearing in mind the root causes of migratory movements and the content of Sendai frame (SF) we believe that SF can serve as a good starting point for solving the problem of mass migrations. The outlined principles and methodology approach in SF does not solve the fundamental sources of problems which are essentially catastrophic events, but the assumption is that through the application of the model set forth in the SF it would also be possible to find causes underlying the disasters brought about by human action. The main source of the problem of climate changes leading to the emergence of the phenomenon of the so-called ecological migrants is inadequate relation of man to nature. When we say man, in this case it refers to the operation of large economic systems that are in their activities guided solely by the obtained profits. Another major driver of migratory movements is political instability and conflicts in an area where again we can perceive the operation of some profit-oriented centres of power. In this context, we recognize the lack of global institutional authority that would affect the removal of the above-stated causes. Civen the nature of the topic and the space available to us our idea is that through the analysis of the SF we point to the possible positive effects of this important document. It is hoped that the strength of the arguments behind the SF may influence the decision-makers so as to comprehend their role in the process of eliminating the risk to the survival of the living world on the planet. Expectations are idealistic, but here is essential not only altruism and the need to preserve our habitat, but also the rational behaviour of global actors in relation to their interest. Unstable environment and the devastation of the existing global civilization system also negatively affects the functioning of the large transnational economic systems. Taking into account their own interest the global actors can contribute to changing the situation in the field of crisis management for the better.

\section{Sendai Framework}

At the third World Conference on Disaster Risk Reduction held in Japan was adopted the Framework for disaster risk reduction. ${ }^{21}$ Guidelines adopted in the said document enable the participating countries through a common methodology, each individually, to contribute to disaster risk reduction on a global scale. As with all international documents so the SF contains quite a number of common areas and references to humanism. However, now we have a document which in addition to declarative statements also offers a concrete methodology, which is, monitoring progress in this area. In SF the main item is the disaster risk reduction and building of community resilience to the said factors with incorporation of elements of sustainable development, the

\footnotetext{
${ }^{21}$ Sendai Framework for Disaster Risk Reduction, The Framework was adopted at the Third UN World Conference on Disaster Risk Reduction in Sendai, Japan, on March 18, 2015 (UNISDR, 2015a).
} 
strategy to combat poverty and finally, elements of the concept of human security, which includes a holistic approach to solving problems in the sphere of citizens' security.

The SF identifies as factors of the increased disaster risks (UNISDR, 2015):

- poverty and inequality,

- climate changes,

- uncontrolled and unplanned urbanization,

- irresponsible environmental policy,

- demographic changes,

- dysfunctional political systems,

- the lack of rules and regulations in areas that can contribute to the disaster risk reduction.

Observing these factors within SF we can conclude that it is all about setting the system on a sound basis and establishing functionality based on legal regulations, that is, the acceptance and application of certain standards in specific areas. The functionality of the system is basically a document adopted in Sendai. The text makes no difference in the need to establish a functional and efficient system compared to other continents, regions and countries. It is certainly one of the most important documents for the establishment of a global system in the process of preparing for the fight against disasters and mitigation of their effects. With the adoption of the universal principles of functioning of the community, businesses and their linking with academic and civil structures we might approach the creation of a global society and the creation of its mechanisms of functioning.

Recognizing the unique living space shared by all inhabitants of the planet, as well as the need to help those countries that are unable to organize their own institutions in accordance with the needs of their citizens, represents a quantum leap in the process of creating a single system for responding to global challenges and threats to human life and the survival of civilization. With the creation of the model in relation to the potential risks and parameters on which to monitor change in the situation is also created an environment in which the owners of capital through appropriate regulations are being stimulated to apply adequate standards in their business systems. We should also bear in mind the significance of economic sanctions for those business entities which do not want to carry out their duties in accordance with their role in the system of prevention and preparation for emergency situations. When it comes to business entities there are several levels, firstly it is about their role in the reactions to emergency situations in terms of a broader social interest, but there is also a need for managers to understand how through the application of appropriate regulations and standards they can contribute to the security of their own business activities and prevention of losses in the situations of disasters. In this context, especially is important the role of international organizations that on the basis of their authority should force all business entities, regardless of the place of their business activities and their financial power to implement the adopted recommendations and standards. In this context especially important are Global and regional platforms for disaster risk reduction and the relevant international and regional forums. 


\section{Securitity}

At the global level should particularly be emphasized the fact of the emergence of a unique business environment. Disorders that occur after a major disaster in a particular location may cause a global crisis that is chain-transmitted to all market and financial transactions irrespective of geographical distance from the scene. Local suffering of the population and the destruction of material goods is becoming a global problem when the drives that are part of the global economic system do not meet their obligations to the other participants in the technological chain. Violation of the functionality of the local system can trigger a wave of refugees that is a problem not only for the country that has been affected by the disaster but is also transferred to the surrounding countries, the wider region, and as we saw in the current migrant crisis to other continents as well. Only under conditions of disasters, many understand the true nature of the connection between all peoples on the planet, regardless of the place of living, origin or social status.

By emphasizing the need for assistance to underdeveloped regions and developing countries the fact is underlined that the developed world should take responsibility for the fate of the world in accordance with its power. This point can be connected with the fact that the previous document (The Framework from Hyogo) did not yield the expected practical results (UNISDR, 2005). Although among the priorities for action in the period from 2005 to 2015 were:

- disaster risk reduction as a priority through the creation of an institutional base at the national and local level,

- creation of an institutional early warning system that should be able to identify, assess and monitor disaster risk changes,

- raising the level of safety culture of the population through the dissemination of knowledge, the application of innovation across all levels of the education system,

- eliminating or at least reducing the underlying risk factors and

- willingness to respond to a disaster in order to raise the level of resilience of the system.

After ten years there is the conclusion that disasters significantly undermine the efforts to achieve sustainability of the development of modern civilization (UNISDR, 2015).

Consistent implementation of the SF in practice offers opportunities of the application for the planned activities whereby significantly reducing the negative impact of human activities on the formation of disasters and simultaneously increasing community resilience to events that cannot be avoided. In effect the SF represents an attempt, on the basis of past experience with similar documents, to avoid their generality and adopt indicators according to which one can measure the level of implementation of the taken-over commitments by the signatories to the document.

Theset goal is aimed at reducing the disaster risks and its consequences, ifsuch consequences occur, and the main prerequisite for success implies a fundamental change in the functioning of modern civilization. Specifically for the start it means that there is an expected change in the evaluation of a business enterprises' economy, raising the level of infrastructural development of the areas, reaching certain standards in the functioning of public services, monitoring the impact of projects on local environmental conditions and the health of the population. Also, very 
important prerequisite for the success is the introduction of appropriate educational contents in a system of continuous education.

SF lists seven global goals whose implementation should contribute to reducing existing risks and preventing the emergence of new ones by raising the resilience of societies and economy. The above mentioned objectives are:

- reducing mortality caused by disasters,

- reducing the number of affected population in the wake of effects of disasters,

- reduction of direct economic losses,

- raising the level of critical infrastructure resilience,

- increase in the number of countries with national and local strategies for disaster risk reduction,

- cooperation and assistance to developing countries in order to support the realization of the projected activities,

- construction and expansion of the capacity of the system for early warning (UNISDR, 2015).

\section{Priorities for action}

The priorities foraction within the SF are set in the spirit of theircharted goals. Understanding the very nature and level of disaster risk is the first step towards solving the problems related to disasters. Raising awareness of all citizens against the risks of disasters ensures that each entity according to their social and professional status may give their contribution to the prevention and mitigation of the effects of the disaster. Knowledge about the possible consequences motivate citizens to engage in the process of risk assessment and preparation for adequate response in emergency situations. Preparations include the collection of relevant information and making projections in accordance with the current situation. The public needs to be periodically informed on the changes that may affect the increase in risk that is, on the measures taken which will reduce the risks or provide an appropriate response in relation to the potential challenges and threats. Distribution of information presupposes a reliable information system that should provide timely information in response to changes of parameters in real time.

The state should create an environment in which all relevant actors will be involved in accordance with their social role. When creating local strategies should be used the existing experience from developed areas adapting to the specifics of the local situation. Strengthening of human, technological and infrastructural prerequisites for successful prevention and mitigation of disasters implies inter-sector cooperation among political, scientific and economic structures. Raising the level of resilience to the effects of disasters includes general education of all citizens in relation to the potential risks and threats.

Strict adherence to the principles of SF is to contribute to the realization of the set objectives promoted through the framework, as well as to allow the signatory countries to solve 
functional problems in the activities of institutions. Within the topic context of this paper the compliance to the principles from Sendai can contribute to solving the problems of internal migrations, reducing the level of disaster risk and build up resilience of the system in relation to the potential catastrophic events.

The approach, according to which every country is responsible for the situation in the area of its jurisdiction works stimulatingly on the local leadership structures that want to make an impression of cooperation in relation to the international community. An objective analysis requires reference to the fact that cooperation with the international community and the fulfilment of the assumed obligations is motivated not only by professionalism of leadership structures, but also by the political interests of those in power who need to prove that they are responsible for the interests of the citizens whose security is their responsibility. Surely in this there is nothing wrong, it is also a chance to show citizens how the application of international conventions and agreements is not inspired exclusively by the interests of big capital. An additional stimulating moment is also the obligation of other signatories to SF to help build a system for disaster management of those countries that are unable to do it themselves. Disaster Management Authority should not have a political connotation, but requires an extremely pragmatic attitude with no ideological moments, it is a field that should contribute to building trust and reducing resistance to the efforts of the constitution of the international institutions system.

The fact is that one of the principles in designing a system for disaster management is taking into account local circumstances which provides the opportunity for a broad mobilization of all relevant stakeholders that can contribute to the creation of an adequate system. The valid assessment of the local situation requires cooperation between all stakeholders in the system so that it would be in accordance with local needs. The country has a coordinating role, while at the operational level an irreplaceable role belongs to the local government (LG). The local government is, according to the nature of its position in the system, the most responsible and the most suitable for the realization of projects in the field of disaster management. In the area of jurisdiction of $L G$ are all elements of the system, its subjects and objects of protection. In the area of local government is realized the primary objective of the risk disaster management system: protection of life and health of the population, living environment, cultural heritage and economic capacities.

It is certainly not a realistic expectation that each local government has its own capacity to assess the vulnerability and building of the disaster response system. Each LG should be able, in accordance with local conditions, to make use of available state resources to reach a qualified assessment, engage economic entities in accordance with their basic activity and location (as elements of response, that is, the subject of protection) and finally, the citizens in accordance with their professional profile, i.e. the location of their homes.

The academic community, with its basic activity, should be included in the risk assessment process, creating a model organization in accordance with local conditions and foreign experience. The academic approach is necessary so that apart from practical solving of a problem into account are to be taken aspects of respect for human rights of all categories of the population, especially 
the most vulnerable (the poor, the elderly and persons with disabilities). The academic community, above all, should provide the appropriate profile of staff that would coordinate the process of assessment and preparation, as professions that are involved in activities often do not have the versatility that allows qualified insight into the situation and needs in relation to the possible course of events.

The risk reduction involves the free flow of information within the circle of students in the process, sharing of information with neighbouring regions, as well as an adequate information flow on a global level.

\section{The case of Serbia}

An example of the Republic of Serbia shows how the above-mentioned risk factors in SF act in practical and concrete circumstances of the particular space. Apart from the fact that the Republic of Serbia in the current migrant transit route it has also problems with internal migrations that are the result of uneven regional development. The space of Serbia was also exposed to heavy floods that have caused great destruction. For all these reasons the Republic of Serbia represents a paradigmatic picture of the situation in the field of disaster protection in the category of developing countries.

Respect and application of the principles set out in the SF provides the designing and building an effective system of disaster management. In the case of the Republic of Serbia can be shown how the local situations with international support can be altered for the better.

1. Poverty and inequality, as a factor influencing the occurrence of cataclysmic situations in Serbia can be viewed through the prism of regional differences, but also as a common place in the context of the drastic fall in GNP in the 90 s of the last century and its stagnation in this century. ${ }^{22}$ The disintegration of the former common state of the southern Slavs led to the devastation of the institutions of the system of state administration and public services which has further aggravated the introduction of the international community sanctions. Emptying of public funds and lowering of wages of employees in public administration and infrastructure systems led to the outflow of the best personnel from that by today's standards represent the critical infrastructure of a country. At the same time moral downfall provoked by miserable incomes of employees led to the collapse of a system of Civil Protection which was functioning quite well in Yugoslavia. The undefined status of public property (nobody's and everybody's) opened the space for the tycoons' activities in the economic area. These are people who in extremely dubious ways seized capital and purchased companies in order to obtain property and not for the sake of their recovery and return to the market. ${ }^{23}$ The transition process saw many resources lost, the resources that were

\footnotetext{
22 The level of realized GDP of the Republic of Serbia still do not exceed the income earned in 1989 when there was a single economic area of Yugoslavia (Kovačević, 2016).

${ }^{23}$ In Serbia, 65\% of the privatization was unsuccessful. Many of the privatized enterprises were important for the system
} 


\section{Security}

critical to the maintenance of and response to the conditions of natural disasters and chemical accidents. All the negative aspects of the relationship with the public interest emerged during the great floods when in the arbitrary operations such aspects came to the fore in areas which are supposed to act preventively in order to mitigate the negative consequences of natural disasters. Simultaneously the collapse of the system brings about the growth of differences between the rich and poor, and underdeveloped regions keep becoming poorer in comparison to developed centres. The population of the east and south Serbia seeks the solution to their economic status in large cities, which further complicates the situation because the absorption capacities of large cities (primarily Belgrade) are limited. The pressure on the infrastructure of cities is huge while many parts of the territory lost population..$^{24}$

2. Climate changes, in the Republic of Serbia also began to manifest through the increased risk of flooding and extreme temperatures. The effects of global warming in Serbia were urther heightened by irresponsible attitude towards the environment. Unplanned and uncontrolled deforestation in the crisis period (during the $90 \mathrm{~s}$ of the last century) was tolerated as a social outlet for the poor citizens preoccupied by survival in the wintertime, and getting earnings from the sale of trees for firewood. The local tycoons took advantage of such a situation as well as members of criminal circles that earned money on the sale of forest timber. ${ }^{25}$ Many parts of the country lost their forest cover in the short term, the cover that acts as a kind of dam against natural disasters since it prevents, or slows down the formation of torrential flooding. In the wake of the floods that hit Serbia in 2015, it can be stated that irresponsibility in relation to the public interest and support showed its true face, so that there also arose the need of adaptation of existing infrastructure facilities to new conditions and the increase flood risks in relation to the projected effects of climate changes.

3. The uncontrolled and unplanned urbanization, the mass influx of people to urban centres was not accompanied by an adequate change of plan documents in the field of construction. ${ }^{26}$ Irresponsible attitude of city zoning services led to the emergence of informal settlements on the outskirts of towns. Formation of unplanned settlements led to the problem of inadequate infrastructure, the increased risk of flooding 27 , inadequate fire-fighting approaches, the lack of adequate public facilities such as schools, health centres and other ancillary facilities that enable a harmonious functioning of the community.

to react in emergency situations (Malešević, 2015).

${ }^{24}$ More than $1 / 4$ of the total population live in the Serbian city of Belgrade.

${ }^{25}$ In the period from 1997 to 2006 in Serbia 109.255m3 of forest was illegally felled (Spasić, Avramović, 2008: 88).

${ }^{26} \mathrm{~A}$ large influx of people into cities without an adequate urban support has resulted in the formation of the largest unplanned (slum-like) settlement in the Balkans (according to some even in the whole of Europe) according the official census of 2011 with 27000 inhabitants while unofficially it has about 40000 inhabitants. Every city in Serbia has its Kaluderica in which people live without basic infrastructure requirements. (Janković, 2015).

${ }^{27}$ The lack of a culture of life in the urban environment, but also in the valleys of the rivers has affected that many settlers made their homes in the flooding areas. By the construction of new facilities settlers directly devastated existing facilities designed to accept excess waters. Drainage channels were used for the construction of residential buildings or fill up garbage sites. 
4. The irresponsible environmental policy, is directly linked to the unplanned urbanization, as well as the irresponsibility of institutions in relation to the location of some facilities of the chemical industry. The formation of settlements in the area close to factories that operate with hazardous materials, or construction of such plants in the immediate vicinity of the village led to the fact that some regions in Serbia have become known for endemic diseases of the respiratory system in humans. ${ }^{28}$ The expansion of settlements without sewerage network directly affected the ecological conditions of life of the population. Converting wells into the septic tanks after laying the water system was a common occurrence in many Serbian towns.

5. Demographic changes, in the Republic of Serbia can be seen through several aspects. First, in the context of the aforementioned spatial imbalance of population, but also as a problem for the most productive part of the population from the area which is usually in an inferior position compared to the rest of the country. Serbia is also exposed to a significant outflow of highly educated people who are looking for better living conditions, leaving the homeland. In addition to moving from underdeveloped rural areas to urban areas many citizens went to developed countries. ${ }^{29}$ The large outflow of population on the basis of emigration exacerbates the trend of depopulation since owing to the difference between births and deaths in Serbia the number population is annually reduced by about 35000 (SORS, 2015).

6. The dysfunction of the political system; In Serbia has long been present ignorant attitude of the intellectual elite towards politics and politicians. It was beneath intellectuals to deal with politics. This space was occupied by people who were not able to excel at their professions and who looked upon politics as an opportunity to get a shortcut to a privileged social status. The political system lost its primary purpose to serve the citizens, in the transition period it was exploited for the sake of plunder of public property and enrichment of local tycoons. The electoral system still reflects negative trends in the political sphere in Serbia. By voting for election lists the voters are denied the right to elect their representatives in Parliament, but that decision is left to the party oligarchy (Đorđević, 2013).

7. The absence of rules and regulations in areas that can contribute to disaster risk reduction. Discontinuity in the functioning of the protection system showed its consequences in the May floods of 2015. The sequence of events and response to the May floods have accelerated the process of preparation and reaction in emergency situations. However, it seems that after the initial intensive work on adapting legislation we once again enter a period of bureaucratic process of dilution. All the documents relevant to the preparation and arrangement of emergency management have not yet been adopted. One of the assumptions of why this is so is the fact that over time political factors' focus of interest shifted to other areas, and professionals do not

\footnotetext{
${ }^{28}$ For example, the town of Pancevo is an illustration of how badly located industrial plants adversely affect the health of the population.

${ }^{29}$ Estimates of the migration of highly educated people are running in the range of several dozen thousands to 600,000 highly educated people. Of course, here we deal with different methodologies, but the fact is that for the small part of the Serbian population the departure of several thousand highly educated people means a great loss (Gucijan, 2016).
} 


\section{Secuurity}

have enough influence on political structures in order to regulate the area in accordance with international standards and local conditions.

\section{APPLICATIONS OF SF TO THE COMMUNITY RESILIENCE IN THE CONTEXT OF MIGRATORY CRISIS}

The main causes of contemporary migratory movements are: economic conditions, environmental conditions, natural disasters, conflicts and violence. If we are able to identify the causes of migration and influence them in a timely way we have a chance to eliminate the main motive for triggering migrants' movements that in effect represents their search for better living conditions.

Figure 1 . Schematic representation of the application of SF to the community resilience in the context of migratory crisis

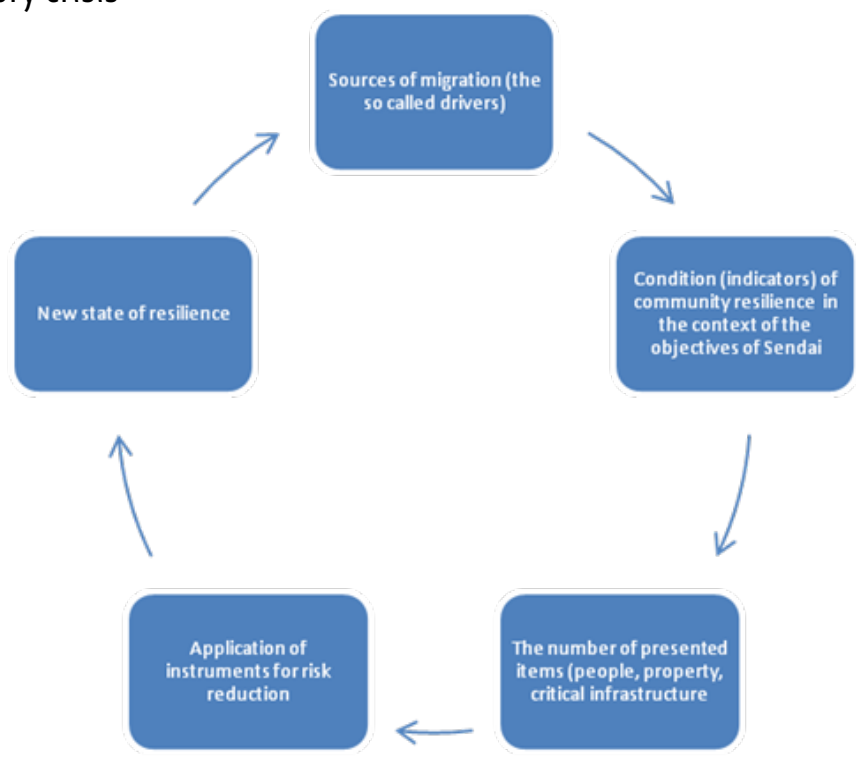

Source: autors.

Figure 1 , allows us to clearly observe the elements of migration management, and at the same time to note a correlation between the approach set forth in SF for disaster management and modern migrations. If we consistently apply the instruments for disaster risk reduction in the observed area we therefore raise the level of communities' resilience to emergencies, reduce the number of exposed people and property affected by the devastating effects and influence the basic motive for initiating the migratory waves. 
Economic opportunities can be recognized as a cause and a consequence of migrations, and also as a disaster to which the SF relates. If the SF is consistently and successfully applied in practice then the majority of the problems associated with economic migration would be resolved. The ecological moment in relation to migration as well as disasters also assumes a multi-sector approach aimed at solving the problems in an area. Natural disasters are increasingly only a natural phenomenon, their roots are to be found in the consequences of the current economic models and the ruthless exploitation of nature with its excessive pollution. The struggle for limited living space and resources necessary for the survival of the population and maintaining the achieved level of standards are the most common causes of conflicts in the modern world. Although to the superficial observer it seems that all this is about something else the greatest number of contemporary migrants flee from the danger which they are daily exposed to, run away from lack of prospects in the area where they lived in search of better living conditions elsewhere.

The realization of the goals set in SF contributes to the elimination or at least reduction of conditions that drive people from their homes in search of a safer life. The strategic objectives are to prevent new and reduce existing risks of catastrophic scenarios. Comprehensiveness of strategies involves taking into account all the elements essential to risk control. The integrated approach includes economic, structural, legal, medical, social, educational, environmental conditions, technology, political and institutional measures. A holistic approach expressed in the SF is compatible with the concept of community resilience, that is, the access present in the concept of human security stating that through the quality of life of citizens who live in a certain area, is also estimated the level of their security. The dynamic model shown in Figure 2 reflects all the complexity of relations within the area of crisis management.

Figure 2. Integrated System Dynamic Model of Human Security and Resilience in Disaster Management.

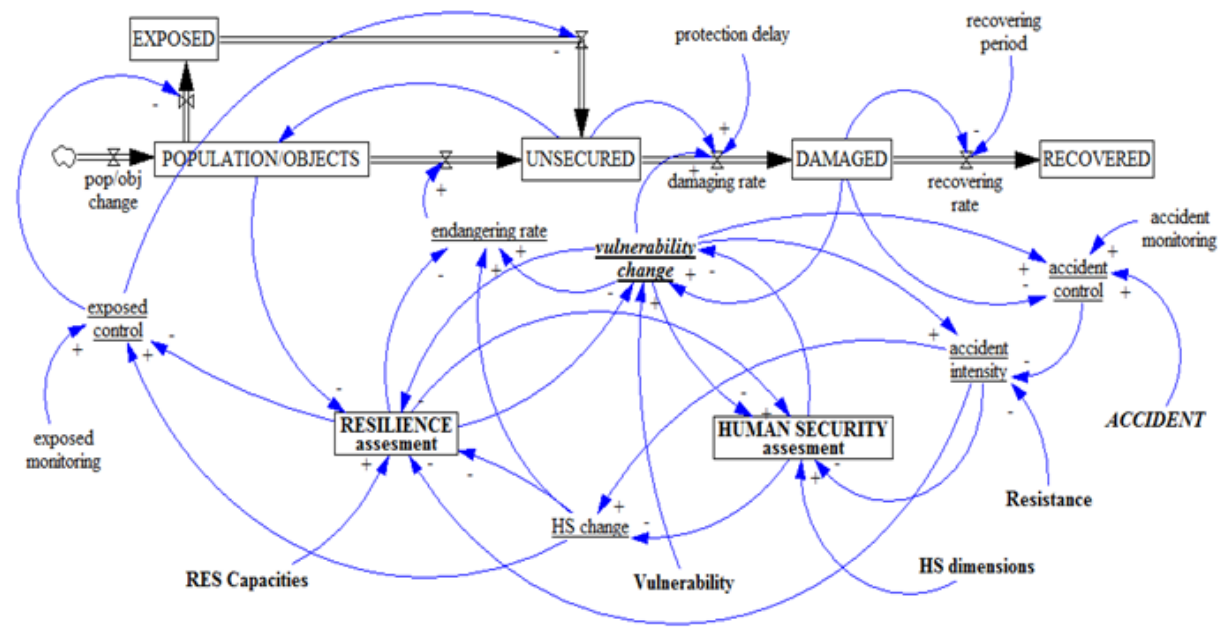

Source: Hayden, 2014. 


\section{Security}

Only multi-sector and multidisciplinary approaches can provide appropriate solutions in the field of disaster management. The complexity of the phenomenon and complexity of an adequate response requires the presence of the academic community in all aspects of preparation, analysis and training of personnel. Due to the effects of possible failures on the lives of people and at the expense of the disaster management material resources the field of disaster management does not tolerate arbitrariness but requires a high level of professionalism.

\section{CONCLUSION}

The complexity of the global ecosystem and interdependence of phenomena, and their effects on all the inhabitants of planet Earth requires a fundamental change in the approach to the problems of modern civilization. The global proliferation of people and goods, and global business networks do not allow the curbing of negative phenomena in the space of one country or region. The connection is manifested at an elementary level, when the effects of the irresponsible behaviour of TNCs in the area of Latin America can feel the residents of the United States due to a number of devastating hurricanes (tornadoes). The planet as a unique eco-system requires a responsible attitude of all of its citizens regardless of where they live. Certainly the greatest responsibility lies on the richest and most powerful countries.

The current migrant crisis shows that there are serious disturbances in the functioning of modern civilization under the existing model. The mere fact that there was agreement on the need for a reaction to the existing situation and coping with disasters at the basis of which are the consequences of irresponsible attitude of people towards the planet gives hope that something can be changed for the better. Understanding the nature of disasters, their causes and consequences opens space for preventing catastrophic situations. However, there is a risk of focusing only on the consequences and their elimination without affecting the causes.

The analysis of the SF in the context of the current refugee crisis provides an opportunity for the professional community to be warned of the danger of losing focus on the cause of the problem. The refugee crisis comes as a result of the lack of an applicable economic model. Treating nature as non-economic good has led to the irresponsible attitude towards natural resources. Inadequate evaluation of input components in the production process and the evaluation of its results realized only through the level of profits are the basis of most of the problems of the modern world. One gets the impression that in many international declarations more care is taken about the economic consequences than the consequences for the environment (Davos). In this context, man as a human being shares the fate of nature as his natural habitat.

Seven goals set forth in the SF have been formulated with the intention to maintain the existing business model which does not contribute to finding the sustainable solutions. Certainly we cannot object anything about the idea of reducing the number of natural disasters together with the effects of such disasters, economic losses and damage to infrastructure. However, the method of coming to this goal never mentions the renunciation of the current socio-economic model. 
Creating strategies for international cooperation and exchange of information and experience does not solve the problem at its source.

Resilience to the potential dangers to which communities are exposed represents a way of reducing the potential victims and material damages of disasters. Disaster risk management not only contributes to sustainable development, but also raises the level of quality of life of people living in an area. By taking adequate measures, creating the institutional mechanisms and developing of space in addition to reducing the direct victims and damages incurred contribute to raising the efficiency of the state administration. These minor positive effects in some situations mean more to citizens than the construction of concrete buildings that should contribute to their protection from natural disasters. Raising the efficiency of institutions in the field of risk management also changes the general environment that affects all aspects of people's lives.

Forecasting, planning and disaster risk reduction in order to protect people and property implies fundamental institutional changes in many areas. These changes suggest establishing an adequate education system that prepares all citizens for an adequate treatment in terms of emergencies, and appropriate educational content for current and future managers of large business and institutional systems. For the successful implementation of the recommendations of the SF it is necessary to apply the appropriate selection of personnel involved in the implementation of risk management strategies, which requires a break with the practice of party clientelism. As the area of emergencies management is of such nature that any deficiency in the system manifests itself in the most drastic form - loss of human lives and enormous material destruction - it will force many of those in power to act more responsibly in accordance with their social functions. In environments in which they turn out to be inadequately prepared for emergency events, the assumption is that in the next elections by casting their votes the citizens will sanction such behaviour.

In the context of linking SF and the migrant crisis, the fact is that through the application of the principle of strengthening the community resilience could be solved some of the problems. By strengthening of public resources the community is prepared to deal with the consequences of disasters at the source where an efficient operation reduces the need for displacement of the population. Also, the existing mechanisms can be used for finding shelter for migrants that come from other areas in order to ensure their adequate treatment. Quick and efficient reaction contributes to the reduction of losses and faster recovery of the affected areas, as well as the rapid return of the affected population in the area that has been hit by the disaster. Construction of appropriate infrastructure through the public-private partnership increases the level of resistance to catastrophic events.

The example of Serbia points to the necessity of the creation and application of international standards in the field of public administration, public finances and operations of transnational economic entities. Although Serbia after the democratic revolution of 2000 became a cooperative member of the international community the internal economic and institutional situation has not significantly changed for the better. Starting from solutions and models being imposed upon Serbia by international factors that are basically not in accordance with local conditions, to tolerating a 
systemic corruption. After almost two decades of transition the results are extremely worrying. Although, according to some estimates into Serbia for various reasons entered over 50 billion USD the positive effects were absent. The international community should insist on the application of controls and standards that are accepted in developed countries when it comes to public administration and public finances. For the development of the situation in Serbia after 2000 responsibility of international factors is at least the same as the local stakeholders. The public in Serbia has accepted structures that were established after the 0ctober changes as something that is in partnership with the developed countries of the West and on that basis it showed its trust in the elections. Closing our eyes to the crime in high politics the international factors seem to be, at the very least, the accomplices of the negative trends on the territory of Serbia (and transition countries in general). Waste of public funds and the economic devastation of the area makes the area of Serbia unsuitable for life of its inhabitants, which drives people to migration and search of better conditions. Disproportion in regional development in addition to internal migration and the imbalance in terms of population density also open the problem regarding control of its territory. Many parts of Serbia were left without population which facilitates cross-border activities of illegal crossings of people. Solving some of the problems listed here was cheaper than the subsequent elimination of the consequences of inadequate regional development policy, or deficiencies in the area of preparation for disaster management. The same applies to the global situation, and the essential question is how much it would cost to solve the problem of refugees in the area of their origin and how much is spent on their integration in the new environment. We hope that the application of the SF is one of the first steps on the long road of solving the paradigmatic crisis of modern civilization. 


\section{Literature}

1. DFID (2011) Defining Disaster Resilience: a DFID Approach Paper. London: Department for International Development.

2. Đorđević, LJ.I. (2013): Ljudska bezbednost - globalni kontekst i primena u Srbiji. Beograd: Institut za uporedno pravo - Dosije.

3. Gucijan, S. (2016) "Niko ne zna koliko nas ima". Politika, The 21st. February 2016. http:// www.politika.rs/scc/clanak/349630 (Visited on 15..12.2017).

4. Hayden, N. (2014) "Resilience in Civil Conflict and Implications for Intervention Policies: An integrative systems approach to policy design". U.S. Department of Energy Office of Scientific and Technical Information. March 18, 2014.

5. https://www.osti.gov/servlets/purl/1335737 (visited on 10.05.2018)

6. Janković A. (2015) “Najveće divlje naselje na Balkanu Kaluđerica kompletno legalizovana do 2022". Blic. The 5th august 2016.

7. http://www.blic.rs/vesti/beograd/najvece-divlje-naselje-na-balkanu-kaludericakompletno-legalizovana-do-2022/8xklms5 (visited on 15.05.2018).

8. Kovačević, M. (2016) "Srbija ostaje u dubokoj ekonomskoj i društvenoj krizi". Balkan Magazin, 15th january 2016.

9. http://www.balkanmagazin.net/nauka/cid144-130425/srbija-ostaje-u-dubokojekonomskoj-i-drustvenoj-krizi-3 (visited on 17.04.2018).

10. Malešević, Lj. (2015) "Eutanazija nad preduzećima koja odavno ne rade". Dnevnik, 21st june 2015. http://www.transparentnost.org.rs/index.php/sr/aktivnosti-2/pressclipping/7750-2015-06-21 (visited on 17.05.2018).

11. SORS (2016) Estimates of population for the Republic of Serbia, 2015, Press Release 30.06.2016. Belgrade: Statistical Office of the Republic of Serbia. http://www.stat. gov.rs/WebSite/public/PageView.aspx?pKey=711\&URL=http://pod2.stat.gov.rs/ ElektronskaBiblioteka2/Pretraga.aspx?pubType $=2$ (visited on 20.12.2016).

12. Spasić D.; Avramović D. (2008) "The Forest Damages Caused by Human Activities". In: Proceedings of international scientific conference Ekolist'08, Ekološka Istina / Ecological Truth. Bor, Sokobanja: Tehnički fakultet u Boru, Univerzitet u Beogradu.

13. UNISDR (2005) "Hyogo Framework for Action 2005-2015: International Strategy for Disaster Reduction". In: World Conference on Disaster Reduction 18-22 January. Kobe, Hyogo: International Strategy for Disaster Reduction.

14. https://www.unisdr.org/2005/wcdr/intergover/official-doc/L-docs/Hyogo-frameworkfor-action-english.pdf (Visited on 20.10.2016)

15. UNISDR (2015) Sendai Framework for Disaster Risk Reduction 2015-2030. Geneva: The United Nations Office for Disaster Risk Reduction. http://www.preventionweb.net/ files/43291_sendaiframeworkfordrren.pdf (Visited on 20.10.2016). 
16. UNISDR (2015a) Making Development Sustainable:The Future of Disaster Risk Management, Global Assessment Report on Disaster Risk Reduction 2015. Geneva: The United Nations Office for Disaster Risk Reduction.

17. https://www.preventionweb.net/english/hyogo/gar/2015/en/gar-pdf/GAR2015_EN.pdf (Visited on 20.10.2016). 